\title{
Análise comparativa das leis e políticas públicas do HIV/AIDS: Brasil e continente latino-americano
}

\author{
Comparative analysis of public HIV/AIDS laws and policies: Brazil and the latin american \\ continent
}

Análisis comparativo de las leyes y políticas públicas sobre VIH/SIDA: Brasil y el continente latinoamericano

Túlio Gabriel de Lima Cavalcanti Torres

ORCID: https://orcid.org/0000-0002-3810-8215 Universidade Federal do Maranhão, Brasil

E-mail: tuliot85@gmail.com

Sueli de Souza Costa

ORCID: https://orcid.org/0000-0003-4127-7324 Universidade Federal do Maranhão, Brasil E-mail: scsueli@gmail.com

Nilson de Jesus Pereira Batalha Júnior

ORCID: https://orcid.org/0000-0002-6325-5655 Universidade Federal do Maranhão, Brasil

E-mail: nilsonbatalha@gmail.com

Luana Mendes Nogueira

ORCID: https://orcid.org/0000-0002-6790-0674 Universidade Federal do Maranhão, Brasil

E-mail: luanamendesnogueira@gmail.com

Taynah Calixto Martins

ORCID: https://orcid.org/0000-0002-9379-8511 Universidade Federal do Maranhão, Brasil E-mail: taynahcalixto@hotmail.com

Izolda Souza Costa

ORCID: https://orcid.org/0000-0003-0899-6845 Universidade Federal do Maranhão, Brasil E-mail: izolda.costa@hotmail.com

\begin{abstract}
Resumo
Esse artigo objetivou identificar os principais indicadores, leis e políticas implementadas por cada um dos países da América Latina e analisar, de forma comparativa, a implementação das deliberações firmadas com os compromissos globais relacionados ao fim da AIDS. Trata-se de um estudo observacional analítico ecológico, cujos dados foram provenientes dos diretórios de informação de domínio público do site Laws And Policies do UNAIDS, tabulados no Excel $2016 \AA$, realizado cálculos de frequência e análise estatística descritiva por meio do software BioStat ${ }^{\circledR}$. Os países que mais comtemplaram as recomendações de leis e políticas de respostas ao HIV/AIDS foram Brasil (79,6\%) e México (74\%). Os países que menos adequaram suas leis e políticas às recomendações do compromisso global foram Peru $(29,6 \%)$, Venezuela $(44,4 \%)$ e Bolívia $(44,4 \%)$. Houve consideráveis discrepâncias na adoção das leis e políticas recomendadas pelo UNAIDS, com destaque positivo para o Brasil e México frente aos demais países Latinoamericanos.
\end{abstract}

Palavras-chave: América latina; Políticas públicas de saúde; Saúde pública; Síndrome de imunodeficiência adquirida.

\begin{abstract}
This article aimed to identify the main indicators, laws and policies implemented by each of the countries in Latin America and to analyze, in a comparative way, the implementation of the deliberations signed with the global commitments related to the end of AIDS. This is an ecological analytical observational study, whose data came from the public domain information directories of the Laws and Policies website of UNAIDS, tabulated in Excel 2016 ${ }^{\circledR}$, carried out frequency calculations and descriptive statistical analysis using software BioStat ${ }^{\circledR}$. The countries that most contemplated the recommendations of laws and policies for responses to HIV / AIDS were Brazil (79.6\%) and Mexico $(74 \%)$. The countries that least adapted their laws and policies to the recommendations of the global
\end{abstract}


commitment were Peru (29.6\%), Venezuela (44.4\%) and Bolivia (44.4\%). There were considerable discrepancies in the adoption of the laws and policies recommended by UNAIDS, with a positive highlight for Brazil and Mexico compared to other Latin American countries.

Keywords: Latin america; Public health policies; Public health; Acquired immunodeficiency syndrome.

\section{Resumen}

Este artículo tuvo como objetivo identificar los principales indicadores, leyes y políticas implementadas por cada uno de los países de América Latina y analizar, de manera comparada, la implementación de las deliberaciones suscritas con los compromisos globales relacionados con el fin del sida. Se trata de un estudio observacional analítico ecológico, cuyos datos provienen de los directorios de información de dominio público del sitio web de Leyes y Políticas de ONUSIDA, tabulado en Excel 2016 ${ }^{\circledR}$, realizado cálculos de frecuencia y análisis estadístico descriptivo utilizando el software BioStat ${ }^{\circledR}$. Los países que más contemplaron las recomendaciones de leyes y políticas de respuesta al VIH / SIDA fueron Brasil (79,6\%) y México (74\%). Los países que menos adaptaron sus leyes y políticas a las recomendaciones del compromiso global fueron Perú (29,6\%), Venezuela (44,4\%) y Bolivia (44,4\%). Hubo discrepancias considerables en la adopción de las leyes y políticas recomendadas por ONUSIDA, con un destaque positivo para Brasil y México en comparación con otros países latinoamericanos.

Palabras clave: América latina; Políticas de salud pública; Salud pública; Síndrome de inmunodeficiencia adquirida.

\section{Introdução}

A história epidemiológica do Vírus da Imunodeficiência Humana (HIV) e da Síndrome da Imunodeficiência Adquirida (AIDS) tem origem em casos que foram detectados, inicialmente, na África e nos Estados Unidos e a relevância da epidemia ganhou notoriedade na década de 1980 (Ayres et al., 2009).

Em 1981, ocorreu aumento exponencial, de modo súbito e inesperado, de doenças classificadas como incomuns, pois apresentavam baixas frequências, como a pneumonia pelo Pneumocystis jiroveci (P. carinii) e o sarcoma de Kaposi (Paksoy, 2020). Essas doenças eram típicas apenas em portadores de imunodepressão avançada, levando a vigilância epidemiológica dos Estados Unidos da América a estabelecer o estado de alerta e buscar mais profunda investigação (Ayres et al., 2009). Os primeiros casos apresentavam um padrão de população acometida, sendo os homossexuais masculinos, até então hígidos, o principal perfil. Diante disso, a sociedade acreditou que se tratava de uma doença gay, o "câncer gay" ou Gay-Related Immune Deficiency (GRID), corroborando a criação de um estigma e preconceito que até hoje perpetua-se (Butturi Junior, 2019).

Contudo, em curto espaço de tempo os casos aumentaram sua incidência e o perfil passou a não ser tão padronizado. Ficou evidenciado que não era uma doença exclusiva dos gays, ocorrendo, em 1982, a modificação da denominação oficial de GRID para Acquired Immune Deficiency Syndrome (AIDS), pelo Centro de Controle e Prevenção de Doenças (CDC) dos Estados Unidos da América (Leite et al., 2020).

O estabelecimento da relação causal só ocorreu em 1983 quando o HIV foi isolado (Sharp \& Hahn, 2011). Os testes de diagnósticos surgiram em 1985, quando foi possível o levantamento dos índices de contágio e revelada a disseminação por todos os continentes do planeta, qualificando-se como uma verdadeira pandemia da infecção (Lopes et al., 2016).

De acordo com os relatórios de 2018, do Programa Conjunto das Nações Unidas sobre HIV/Aids (UNAIDS), as estatísticas globais evidenciam que 37,9 milhões de pessoas em todo o mundo estejam vivendo com HIV, 1,7 milhão por novas infecções (AVERT, 2020). Durante o mesmo ano, 770 mil pessoas morreram de doenças relacionadas à aids. Desde o início da epidemia, 74,9 milhões de pessoas foram infectadas pelo HIV e 32 milhões de pessoas morreram de doenças relacionadas à aids, face de uma patologia agressiva (AVERT, 2020).

Desde os primeiros casos da síndrome da imunodeficiência adquirida, órgãos públicos com o apoio de inúmeras instituições não governamentais, por todo o mundo, buscaram modos de enfrentar a pandemia. Para tal, recursos crescentes foram empregados à medida que abrolharam as primeiras políticas e leis que visam à redução das taxas de infecções, controle e diagnóstico dos casos atuais, cobertura de tratamento e, por fim, a erradicação da AIDS (Villarinho et al., 2013).

A evolução alcançada ao longo dos anos, desde os primeiros casos, é produto do engajamento político e da busca de 
estratégias de combate a partir, principalmente, das resoluções internacionais, focando em populações de risco elevado, visando ao controle epidemiológico através da expansão da cobertura da terapia e em estratégias de prevenção (Moura \& Lemos, 2016).

Quanto às políticas e estratégias, os programas de atenção à prevenção primária abordam os comportamentos saudáveis, ou seja, é o conjunto de ações que visam evitar a doença na população, removendo os fatores causais, e visam a diminuição da incidência da doença; entretanto ainda é negligenciada (Almeida, 2005). Dessa forma, na prática, é o diagnóstico do vírus do HIV que constitui a oportunidade para a educação do paciente e promoção da saúde, revelando defasagem na aplicação da prevenção. Entre as intervenções de prevenção, o comportamento de risco deve ser prioridade, enquanto a adesão às terapias medicamentosa e psicossocial melhoram a qualidade de vida do portador. Em contrapartida, o conhecimento sobre a doença e como evitá-la não necessariamente faz as pessoas incorporarem o comportamento preventivo, sendo fundamental políticas de educação continuada e pontuais, sobretudo nas populações mais vulneráveis e em locais endêmicos (Rabkin \& El-Sadr, 2011).

A pandemia evidenciou a necessidade de respostas e comprometimento coletivo, dentre as quais estão incluídas as políticas e leis oficiais em seus mais diversos âmbitos (Narayan et al., 2011). O conhecimento a respeito do HIV/AIDS levou os especialistas a postularem três máximas da realidade que são inquestionáveis em relação à doença: a primeira é que a busca pela cura e a luta contra a pandemia deve ser global e não nacional; a segunda é que a prevenção deve ser inevitavelmente ligada ao diagnóstico e tratamento precoce, o que significa o uso de abordagens eficazes ligadas à comunidade com sistemas de saúde organizados e, por fim, embora o comportamento desempenhe papel importante na questão do risco de se contrair o HIV, os esforços de prevenção necessitam integrar abordagens comportamentais associadas a abordagens biomédicas para que se complementem na redução do agravo (Narayan et al., 2011).

Os dados mais atuais a respeito da epidemiologia no continente latino americano são preocupantes. Na América Latina, segundo dados fornecidos pela Organização Global de HIV e AIDS (AVERT), para o ano de 2018, foi estimado que 1,9 milhões de pessoas vivam com o HIV. Destes, $63 \%$ dos adultos e $48 \%$ das crianças estão em tratamento com antirretrovirais. No mesmo ano, foram notificadas 100.000 novas infecções. A epidemia de HIV concentrava-se entre homens que fazem sexo com homens (HSH), profissionais do sexo e usuários de droga por via de injeções (UNAIDS Brasil, 2019a; ONU, 2019).

O último relatório do Unaids revelou desaceleração da diminuição de casos em nível global, levando a Organização das Nações Unidas (ONU) a qualificar o status como preocupante. Concomitantemente, na América Latina, o combate ao HIV sofreu um revés, uma vez que o mesmo relatório apresentou que a taxa de contágio do vírus na região cresceu $7 \%$ entre 2010 e 2018 (ONU, 2019).

$\mathrm{Na}$ análise da reexpansão do vírus, o Brasil tem participação fundamental, ao responder por mais da metade dos casos, registrando $21 \%$ de aumento e arrastando a região para os números vermelhos. O índice de novos contágios a cada ano cresceu $34 \%$ no Chile, $22 \%$ na Bolívia e 21\% na Costa Rica. Também aumentaram as infecções no Uruguai, Honduras, Guatemala e Argentina, mas em cifras inferiores a 10\%. Além do Leste Europeu e Ásia Central, a América Latina apareceu como uma das regiões do mundo com os piores dados na luta contra o HIV (ONU, 2019). Desta forma, neste trabalho procurou-se analisar, de forma comparativa, as políticas e leis relacionadas à resposta à epidemia HIV/AIDS implementadas nos países da América Latina, a fim de identificar progresso, lacunas ainda presentes e desafios no continente.

\section{Metodologia}

Trata-se de um estudo observacional analítico ecológico, qualitativo (Pereira, Shitsuka, Parreira \& Shitsuka, 2018) 
que avaliou a relação existente entre as principais políticas, leis e indicadores do HIV implementados por cada um dos países da América Latina em curso no ano de 2020.

Este estudo foi realizado com dados provenientes dos diretórios de informação de domínio público do site Laws And Policies (http://lawsandpolicies.unaids.org./) do UNAIDS, a partir dos Instrumentos de Compromissos e Políticas Nacionais (NCPI) e contemplou os países da América Latina (Argentina, Bolívia, Brasil, Chile, Colômbia, Costa Rica, Equador, El Salvador, Guatemala, Honduras, México, Nicarágua, Panamá, Paraguai, Peru, Uruguai e Venezuela).

O estudo analisou 23 variáveis e organizou-as em cinco categorias: Estratégias de Diagnóstico e Tratamento (Teste de HIV; Terapia Antirretroviral; Carga Viral; Resistência aos Medicamentos para o HIV; Adesão e Retenção); Estratégias de Vigilância Epidemiológica (Estratégia de HIV; Monitoramento e Avaliação; Sistema de Informação; Vigilância; Sistemas de Monitoramento de Pacientes; 90-90-90); Políticas de Prevenção do HIV para os Grupos de Risco (Prevenção do HIV para Profissionais do Sexo; Prevenção de HIV para Homens que Fazem Sexo com Homens; Prevenção de HIV para Pessoas que Injetam Drogas; Serviços de Prevenção do HIV para Prisioneiros; Preservativos ); População Jovem e Infecções Sexualmente Transmissíveis (Prevenção do HIV Entre Meninas Adolescentes, Mulheres Jovens e Seus Parceiros Masculinos; Os Jovens; Infecções Sexualmente Transmissíveis); Diretrizes de Atenção à Saúde Materna e a Transmissão Vertical (Prevenção da Transmissão de Mãe Para Filho do HIV; Eliminação da Transmissão de Sífilis de Mãe para Filho; Diagnóstico Infantil Precoce; Envolvimento da Comunidade na Prevenção da Transmissão Vertical ).

Para a organização dos dados, utilizou-se tabelas no software Excel® e a apresentação se deu por meio de tabela e gráficos de distribuição de frequências, absolutas e relativas. Para a obtenção das características do estudo, a análise das variáveis foi realizada por meio do software estatístico BioStat ${ }^{\circledR}$.

Por tratar-se de um estudo que utiliza dados provenientes de banco de dados secundários de domínio público, não foi necessária submissão e aprovação em Comitê de Ética em Pesquisa, de acordo com a Resolução No 466, de 12 de dezembro de 2012, do Conselho Nacional de Saúde.

\section{Resultados}

Os dados obtidos demostraram que, entre os 59 itens apreciados no estudo, os países que mais comtemplaram as recomendações de leis e políticas de respostas ao HIV/Aids foram Brasil (79,6\%) e México (74\%), enquanto os que menos adequaram suas leis e políticas às recomendações do compromisso global foram Peru (29,6\%), Venezuela (44,4\%) e Bolívia (44,4\%), (Figura 1).

Pode-se observar no gráfico box plot (Figura 2) que, em relação às estratégias, a que mais foi contemplada foi Diretrizes de Atenção à Saúde Materna e Transmissão Vertical, e as menos contempladas foram Estratégias de Diagnóstico e Tratamento e Estratégias de Vigilância Epidemiológica.

Quanto às Estratégias de Diagnóstico e Tratamento (Tabela 1), apenas 41,1\% dos países adotaram totalmente as recomendações das diretrizes da OMS de 2015 sobre os serviços de teste de HIV. Do total, 82,3\% dos países não possuem política nacional de autoteste de HIV. Apenas 23,5\% dos países completaram as recomendações das diretrizes consolidadas da OMS de 2016 a respeito da terapia antirretroviral para adultos. As mesmas recomendações para a população pediátrica foram completadas em $41,1 \%$. Apenas $41,1 \%$ dos países concluíram as diretrizes consolidadas da OMS de 2018 adaptadas ao país sobre o uso de ARVs para o tratamento e prevenção do HIV. Além disso, em 52\% dos países não é possível iniciar o TARV no mesmo dia do diagnóstico de HIV. 
Research, Society and Development, v. 10, n. 14, e352101421905, 2021

(CC BY 4.0) | ISSN 2525-3409 | DOI: http://dx.doi.org/10.33448/rsd-v10i14.21905

Figura 1. Ranking dos países da América Latina por variáveis contempladas no estudo para leis e políticas do HIV/AIDS.

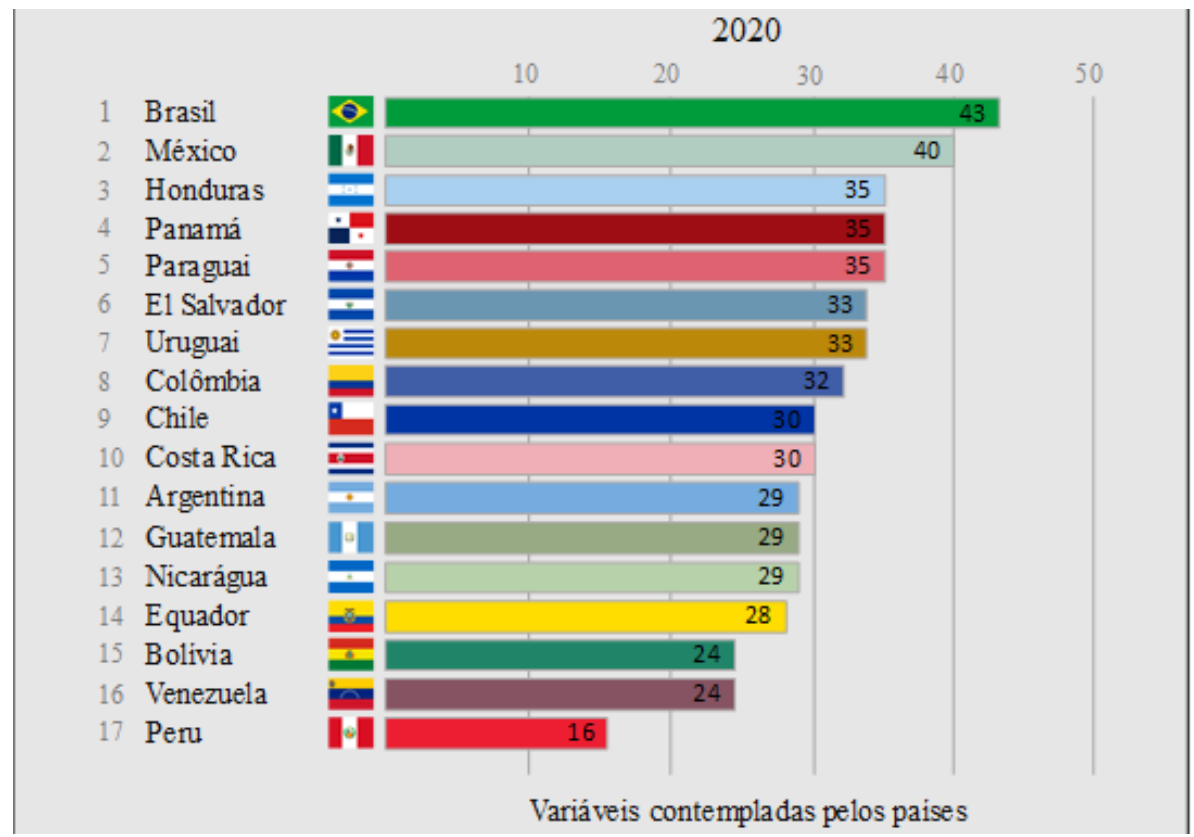

Fonte: Elaborado pelos autores com base em Laws and Policies (UNAIDS) (2020).

Figura 2. Gráfico box plot das estratégias das leis e políticas do HIV/Aids na América Latina.

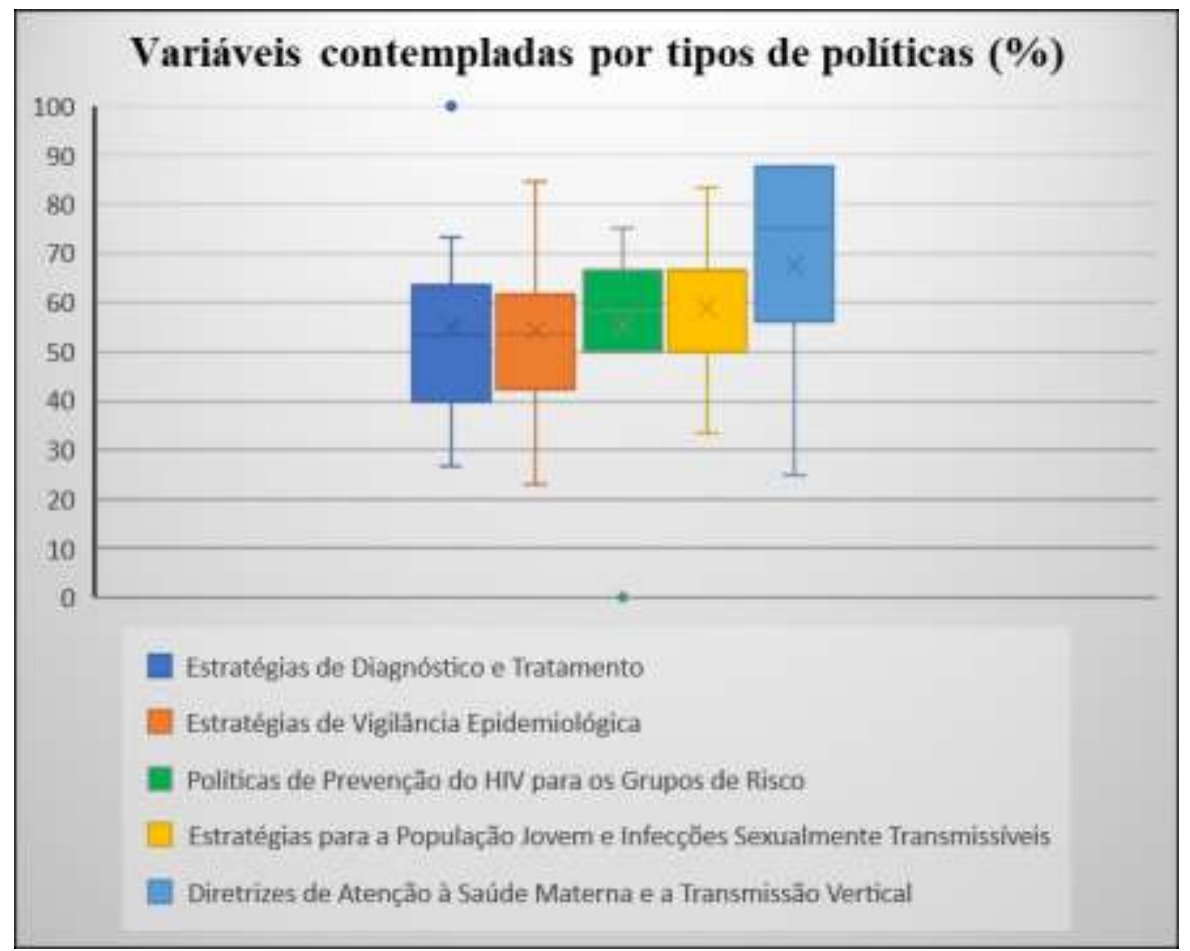

Fonte: Elaborado pelos autores com base em Laws and Policies (UNAIDS) (2020). 
Tabela 1. Distribuição de frequência (\%) dos itens relativos às estratégias e políticas de combate ao HIV/AIDS.

CATEGORIAS E

VARIÁVEIS

ESTADOS LATINO-AMERICANOS

FREQUÊNCIA

$(\%)$

\begin{tabular}{|c|c|c|c|c|c|c|c|c|c|c|c|c|c|c|c|c|c|c|}
\hline & $\mathbf{A R}$ & BO & BR & $\mathbf{C L}$ & $\mathrm{CO}$ & CR & EC & GT & HN & MX & NI & $\mathbf{P A}$ & $\mathbf{P E}$ & PY & SV & UY & VE & \\
\hline \multicolumn{19}{|l|}{$\begin{array}{l}\text { Itens relativos às estratégias } \\
\text { de diagnóstico e tratamento }\end{array}$} \\
\hline \multicolumn{19}{|l|}{ Teste de HIV } \\
\hline $\begin{array}{l}\text { País adotou recomendações das } \\
\text { diretrizes da OMS de } 2015 \\
\text { sobre serviços de teste de HIV. }\end{array}$ & $\mathrm{T}$ & $\mathrm{P}$ & $\mathrm{T}$ & $\mathrm{T}$ & $\mathrm{P}$ & $\mathrm{P}$ & $\mathrm{P}$ & $\mathrm{P}$ & $\mathrm{P}$ & $\mathrm{T}$ & $\mathrm{T}$ & $\mathrm{T}$ & $\mathrm{P}$ & $\mathrm{T}$ & Não & $\mathrm{P}$ & Não & $\begin{array}{c}7 \mathrm{~T}(41,1 \%) \\
8 \mathrm{P}(47 \%) \\
2 \text { Não }(11,7 \%)\end{array}$ \\
\hline $\begin{array}{l}\text { O país tem uma política } \\
\text { nacional de autoteste de HIV. }\end{array}$ & Não & Não & Sim & Não & Sim & Não & Não & Não & Não & Sim & Não & Não & Não & Não & Não & Não & Não & $\begin{array}{l}3 \operatorname{Sim}(17,6 \%) \\
14 \text { Não }(82,3 \%)\end{array}$ \\
\hline $\begin{array}{l}\text { Política de provisão de testes de } \\
\text { HIV gratuita para todos, gratuita } \\
\text { para alguns ou a um custo. }\end{array}$ & G & G & G & $\mathrm{P}$ & G & $\mathrm{P}$ & G & G & G & G & G & G & $\mathrm{P}$ & G & G & $\mathrm{P}$ & G & $\begin{array}{c}13 \mathrm{G}(76,4 \%) \\
4 \mathrm{P}(23,5 \%)\end{array}$ \\
\hline $\begin{array}{l}\text { O país tem uma política / } \\
\text { estratégia nacional para vincular } \\
\text { o teste de HIV e } \\
\text { aconselhamento e inscrição em } \\
\text { cuidados. }\end{array}$ & Sim & Sim & Sim & Sim & Sim & Sim & Sim & Sim & Sim & Sim & Sim & Sim & Não & Sim & Sim & Sim & Sim & $\begin{array}{c}16 \operatorname{Sim}(94,1 \%) \\
1 \text { Não }(5,8 \%)\end{array}$ \\
\hline \multicolumn{19}{|l|}{ Terapia Antirretroviral } \\
\hline $\begin{array}{l}\text { Recomendações das diretrizes } \\
\text { consolidadas da OMS de } 2016 \\
\text { adaptadas ao país: terapia } \\
\text { antirretroviral para adultos. }\end{array}$ & $\mathrm{C}$ & EA & $\mathrm{C}$ & EA & Não & EA & DND & EA & EA & $\mathrm{C}$ & EA & DND & DND & EA & EA & EA & $\mathrm{C}$ & $\begin{array}{c}4 \text { C }(23,5 \%) \\
9 \text { EA }(52,9 \%) \\
1 \text { Não }(5,8 \%) \\
3 \text { DND }(17,6 \%)\end{array}$ \\
\hline
\end{tabular}




\begin{tabular}{|c|c|c|c|c|c|c|c|c|c|c|c|c|c|c|c|c|c|c|}
\hline \multirow[t]{2}{*}{$\begin{array}{l}\text { CATEGORIAS E } \\
\text { VARIÁVEIS } \\
\end{array}$} & \multicolumn{17}{|c|}{ ESTADOS LATINO-AMERICANOS } & \multirow{2}{*}{$\begin{array}{c}\text { FREQUÊNCIA } \\
(\%)\end{array}$} \\
\hline & $\mathbf{A R}$ & BO & $\mathbf{B R}$ & $\mathbf{C L}$ & $\mathrm{CO}$ & $\mathbf{C R}$ & EC & GT & HN & MX & NI & $\mathbf{P A}$ & $\mathbf{P E}$ & PY & SV & UY & VE & \\
\hline $\begin{array}{l}\text { Recomendações das diretrizes } \\
\text { consolidadas da OMS de } 2016 \\
\text { adaptadas ao país: terapia } \\
\text { antirretroviral pediátrica. } \\
\text { As diretrizes consolidadas da }\end{array}$ & $\mathrm{C}$ & EA & $\mathrm{C}$ & EA & Não & $\mathrm{C}$ & DND & EA & $\mathrm{C}$ & $\mathrm{C}$ & EA & DND & DND & EA & $\mathrm{C}$ & EA & $\mathrm{C}$ & $\begin{array}{c}7 \text { C }(41,1 \%) \\
6 \text { EA }(35,2 \%) \\
1 \text { Não }(5,8 \%) \\
3 \text { DND }(17,6 \%)\end{array}$ \\
\hline $\begin{array}{l}\text { OMS de } 2018 \text { adaptadas ao } \\
\text { país sobre o uso de ARVs para } \\
\text { o tratamento e prevenção da } \\
\text { infecção por HIV. }\end{array}$ & EA & EA & $\mathrm{C}$ & $\mathrm{C}$ & Não & EA & EA & EA & EA & $\mathrm{C}$ & EA & $\mathrm{C}$ & $\mathrm{C}$ & EA & Não & $\mathrm{C}$ & $\mathrm{C}$ & $\begin{array}{c}7 \mathrm{C}(41,1 \%) \\
8 \text { EA }(47,1 \%) \\
2 \text { Não }(11,7 \%)\end{array}$ \\
\hline $\begin{array}{l}\text { Possível iniciar o TARV no } \\
\text { mesmo dia do diagnóstico de } \\
\text { HIV. }\end{array}$ & Não & Não & Sim & Sim & Não & Não & Não & Sim & Não & Sim & Não & Sim & DND & Sim & Não & Não & Sim & $\begin{array}{l}7 \operatorname{Sim}(41,1 \%) \\
9 \text { Não }(52,9 \%) \\
1 \text { DND }(5,8 \%) \\
\end{array}$ \\
\hline \multicolumn{19}{|l|}{ Carga Viral } \\
\hline $\begin{array}{l}\text { Limiar medido de sucesso de } \\
\text { supressão de carga viral } \\
\left(_{\text {cópias } / \mathrm{ml})^{\mathrm{a}} \text {. }}\right. \\
\text { Política nacional de teste de }\end{array}$ & $<50$ & $<1000$ & $<50$ & $<200$ & $<1000$ & $<20$ & $<50$ & $<1000$ & $<400$ & $<50$ & $<1000$ & $<50$ & DND & $<1000$ & $<50$ & $<50$ & $<50$ & $\begin{array}{c}10<200(58,8 \%) \\
6>200(35,2 \%) \\
1 \text { DND }(5,8 \%) \\
15 \mathrm{~J}(88,2 \%)\end{array}$ \\
\hline $\begin{array}{l}\text { carga viral de rotina: para } \\
\text { adultos e adolescentes. }\end{array}$ & I & IP & I & I & $\mathrm{I}$ & $\mathrm{I}$ & I & I & $\mathrm{I}$ & I & $\mathrm{I}$ & I & I & $\mathrm{I}$ & $\mathrm{I}$ & I & NI & $\begin{array}{l}1 \mathrm{IP}(5,8 \%) \\
1 \mathrm{NI}(5,8 \%)\end{array}$ \\
\hline $\begin{array}{l}\text { Frequência recomendada de } \\
\text { teste de carga viral na política } \\
\text { nacional }^{\text {b. }}\end{array}$ & $4 \mathrm{M}$ & $12 \mathrm{M}$ & $6 \mathrm{M}$ & $12 \mathrm{M}$ & $6 \mathrm{M}$ & $\begin{array}{l}12 \\
M\end{array}$ & $6 \mathrm{M}$ & $12 \mathrm{M}$ & $6 \mathrm{M}$ & $6 \mathrm{M}$ & $12 \mathrm{M}$ & $6 \mathrm{M}$ & $12 \mathrm{M}$ & $12 \mathrm{M}$ & $6 \mathrm{M}$ & $\begin{array}{l}12 \\
M\end{array}$ & $12 \mathrm{M}$ & $\begin{array}{c}8<6 \mathrm{M}(47 \%) \\
9>6 \mathrm{M}(52,9 \%)\end{array}$ \\
\hline \multicolumn{19}{|l|}{$\begin{array}{l}\text { Resistencia Aos } \\
\text { Medicamentos }\end{array}$} \\
\hline $\begin{array}{l}\text { Sistemas implantados para } \\
\text { monitorar a resistência aos } \\
\text { medicamentos antirretrovirais. }\end{array}$ & Não & Não & Sim & Sim & Não & Não & Não & Não & Não & Sim & Não & Sim & Sim & Sim & Não & Não & Não & $\begin{array}{c}6 \operatorname{Sim}(35,2 \%) \\
11 \text { Não }(64,7 \%)\end{array}$ \\
\hline Adesão E Retenção & & & & & & & & & & & & & & & & & & \\
\hline
\end{tabular}


Research, Society and Development, v. 10, n. 14, e352101421905, 2021

(CC BY 4.0) | ISSN 2525-3409 | DOI: http://dx.doi.org/10.33448/rsd-v10i14.21905

\begin{tabular}{|c|c|c|c|c|c|c|c|c|c|c|c|c|c|c|c|c|c|c|}
\hline \multirow{2}{*}{$\begin{array}{l}\text { CATEGORIAS E } \\
\text { VARIÁVEIS }\end{array}$} & \multicolumn{17}{|c|}{ ESTADOS LATINO-AMERICANOS } & \multirow{2}{*}{$\begin{array}{c}\text { FREQUÊNCIA } \\
(\%) \\
\end{array}$} \\
\hline & $\mathbf{A R}$ & BO & BR & $\mathbf{C L}$ & CO & $\mathbf{C R}$ & $\mathbf{E C}$ & GT & HN & MX & NI & PA & PE & PY & SV & $\mathbf{U Y}$ & VE & \\
\hline $\begin{array}{l}\text { Política / estratégia nacional de } \\
\text { apoio à adesão. }\end{array}$ & Não & Sim & Sim & Sim & Sim & Sim & Não & Sim & Sim & Sim & Sim & Sim & Sim & Sim & $\operatorname{Sim}$ & Sim & Sim & $\begin{array}{l}15 \operatorname{Sim}(88,2 \%) \\
2 \text { Não }(11,7 \%)\end{array}$ \\
\hline $\begin{array}{l}\text { Política / estratégia nacional de } \\
\text { retenção em TARV. }\end{array}$ & Não & Sim & Sim & Sim & Sim & Sim & Não & Não & Sim & Sim & Sim & Sim & Sim & Sim & Sim & Sim & Sim & $\begin{array}{l}14 \operatorname{Sim}(82,3 \%) \\
3 \text { Não }(17,6 \%)\end{array}$ \\
\hline $\begin{array}{l}\text { Programas de alfabetização } \\
\text { sobre tratamento disponíveis } \\
\text { para pessoas que vivem com } \\
\text { HIV. }\end{array}$ & Não & Não & Sim & Sim & Sim & Sim & Sim & Não & Sim & Sim & Não & Não & Não & Não & Não & Sim & Não & $\begin{array}{c}8 \operatorname{Sim}(47 \%) \\
9 \text { Não }(52,9 \%)\end{array}$ \\
\hline \multicolumn{19}{|l|}{$\begin{array}{l}\text { Itens relativos às estratégias } \\
\text { de vigilância epidemiológica }\end{array}$} \\
\hline \multicolumn{19}{|l|}{ Estratégias HIV } \\
\hline $\begin{array}{l}\text { Estratégia / política nacional } \\
\text { que orienta a resposta ao SIDA. }\end{array}$ & Sim & Sim & Sim & Sim & Sim & Sim & Sim & Sim & Sim & Sim & Sim & Sim & Sim & Sim & Sim & Sim & Sim & $17 \operatorname{Sim}(100 \%)$ \\
\hline $\begin{array}{l}\text { Estratégia / política nacional de } \\
\text { HIV revisada nos últimos } 2 \\
\text { anos. }\end{array}$ & Sim & Sim & Sim & Sim & Sim & Sim & Sim & Sim & Sim & Sim & Não & Sim & Não & Sim & Sim & Sim & Não & $\begin{array}{l}14 \operatorname{Sim}(82,3 \%) \\
3 \text { Não }(17,6 \%)\end{array}$ \\
\hline \multicolumn{19}{|l|}{ Monitoramento E Avaliação } \\
\hline $\begin{array}{l}\text { Existe um plano / estratégia } \\
\text { nacional de monitoramento e } \\
\text { avaliação de HIV. }\end{array}$ & Sim & Sim & Sim & Sim & Sim & Sim & Sim & Sim & Sim & Sim & Sim & Sim & Sim & Sim & Sim & Sim & Sim & $17 \operatorname{Sim}(100 \%)$ \\
\hline $\begin{array}{l}\text { Plano / estratégia nacional de } \\
\text { monitoramento e avaliação de } \\
\text { HIV atualizado nos últimos } 2 \\
\text { anos. }\end{array}$ & Sim & Sim & Sim & Sim & Sim & Não & Não & Não & Sim & Sim & Não & Não & Não & Sim & Sim & Não & Não & $\begin{array}{l}9 \operatorname{Sim}(52,9 \%) \\
8 \text { Não }(47 \%)\end{array}$ \\
\hline \multicolumn{19}{|l|}{ Sistema De Informação } \\
\hline $\begin{array}{l}\text { Coleta de dados de rotina sobre } \\
\text { a prestação de serviços de HIV } \\
\text { institucionalizada em um } \\
\text { sistema de informação. }\end{array}$ & Sim & Sim & Sim & Sim & Sim & Sim & Sim & Sim & Sim & Sim & Sim & Sim & Sim & Sim & Sim & Sim & Sim & $17 \operatorname{Sim}(100 \%)$ \\
\hline
\end{tabular}




\begin{tabular}{|c|c|c|c|c|c|c|c|c|c|c|c|c|c|c|c|c|c|c|}
\hline \multirow[t]{2}{*}{$\begin{array}{l}\text { CATEGORIAS E } \\
\text { VARIÁVEIS }\end{array}$} & \multicolumn{17}{|c|}{ ESTADOS LATINO-AMERICANOS } & \multirow{2}{*}{$\begin{array}{c}\text { FREQUÊNCIA } \\
(\%)\end{array}$} \\
\hline & $\mathbf{A R}$ & BO & BR & CL & $\mathrm{CO}$ & CR & EC & GT & HN & MX & NI & PA & $\mathbf{P E}$ & PY & SV & $\mathbf{U Y}$ & VE & \\
\hline $\begin{array}{l}\text { CATEGORIAS E } \\
\text { VARIÁVEIS }\end{array}$ & \multicolumn{17}{|c|}{ ESTADOS LATINO-AMERICANOS } & $\begin{array}{c}\text { FREQUÊNCIA } \\
(\%)\end{array}$ \\
\hline & $\mathbf{A R}$ & BO & $\mathbf{B R}$ & CL & $\mathrm{CO}$ & CR & EC & GT & HN & MX & NI & $\mathbf{P A}$ & $\mathbf{P E}$ & PY & SV & UY & VE & \\
\hline $\begin{array}{l}\text { Sistema de informação de saúde } \\
\text { em funcionamento. }\end{array}$ & A & EL & EL & A & EL & A & A & A & A & A & A & A & A & A & A & A & $\mathrm{PP}$ & $\begin{array}{c}13 \mathrm{~A}(76,4 \%) \\
3 \mathrm{EL}(17,6 \%) \\
1 \mathrm{PP}(5,9 \%)\end{array}$ \\
\hline \multicolumn{19}{|l|}{ Vigilância } \\
\hline $\begin{array}{l}\text { Vigilância sentinela conduzida: } \\
\text { participantes da clínica pré-natal. }\end{array}$ & Não & Sim & Sim & Não & Sim & Não & DND & Sim & Não & Não & Sim & Não & DND & Sim & Não & Sim & Não & $\begin{array}{c}7 \operatorname{Sim}(41,1 \%) \\
8 \text { Não }(47 \%) \\
2 \operatorname{DND}(11,7 \%)\end{array}$ \\
\hline $\begin{array}{l}\text { Vigilância sentinela conduzida: } \\
\text { profissionais do sexo. }\end{array}$ & Não & Não & Sim & Não & Não & Não & DND & Sim & Sim & Sim & Sim & Sim & DND & Sim & Sim & Sim & Não & $\begin{array}{c}9 \operatorname{Sim}(52,9 \%) \\
6 \text { Não }(35,2 \%) \\
2 \text { DND }(11,7 \%)\end{array}$ \\
\hline $\begin{array}{l}\text { Vigilância sentinela conduzida: } \\
\text { homens que fazem sexo com } \\
\text { homens. }\end{array}$ & Não & Não & Sim & Não & Não & Sim & DND & Sim & Sim & Sim & Sim & Sim & DND & Sim & Sim & Não & Não & $\begin{array}{c}9 \operatorname{Sim}(52,9 \%) \\
6 \text { Não }(35,2 \%) \\
2 \operatorname{DND}(11,7 \%)\end{array}$ \\
\hline $\begin{array}{l}\text { Vigilância sentinela conduzida: } \\
\text { pessoas que injetam drogas. }\end{array}$ & Não & Não & Sim & Não & Não & Não & DND & Não & Não & Sim & Não & Não & DND & Não & Não & Não & Não & $\begin{array}{l}2 \operatorname{Sim}(11,7 \%) \\
13 \text { Não }(76,4 \%) \\
2 \operatorname{DND}(11,7 \%)\end{array}$ \\
\hline \multicolumn{19}{|l|}{$\begin{array}{l}\text { Sistemas De Monitoramento } \\
\text { De Pacientes }\end{array}$} \\
\hline $\begin{array}{l}\text { Indicadores e ferramentas do } \\
\text { sistema de monitoramento de } \\
\text { pacientes atualizados usando as } \\
\text { diretrizes de monitoramento de } \\
\text { pacientes da OMS } 2017 .\end{array}$ & Não & $\mathrm{P}$ & $\mathrm{P}$ & $\mathrm{P}$ & Não & Não & Não & $\mathrm{P}$ & Sim & $\mathrm{P}$ & $\operatorname{sim}$ & Não & $\mathrm{P}$ & Sim & $\mathrm{P}$ & Não & Não & $\begin{array}{l}3 \operatorname{Sim}(17,6 \%) \\
7 \text { Não }(41,1 \%) \\
7 \text { P }(41,1 \%)\end{array}$ \\
\hline $90-90-90$ & & & & & & & & & & & & & & & & & & \\
\hline
\end{tabular}




\begin{tabular}{|c|c|c|c|c|c|c|c|c|c|c|c|c|c|c|c|c|c|c|}
\hline \multirow{2}{*}{$\begin{array}{l}\text { CATEGORIAS E } \\
\text { VARIÁVEIS } \\
\end{array}$} & \multicolumn{17}{|c|}{ ESTADOS LATINO-AMERICANOS } & \multirow{2}{*}{$\begin{array}{c}\text { FREQUENNCIA } \\
(\%)\end{array}$} \\
\hline & $\mathbf{A R}$ & BO & BR & $\mathbf{C L}$ & CO & $\mathbf{C R}$ & EC & GT & HN & MX & NI & $\mathbf{P A}$ & $\mathbf{P E}$ & PY & SV & UY & VE & \\
\hline $\begin{array}{l}\text { Revisão da qualidade dos dados } \\
\text { realizada para determinar a } \\
\text { precisão do número de pessoas } \\
\text { em tratamento em nível nacional. }\end{array}$ & $\mathrm{EE}$ & $\mathrm{C}$ & $\mathrm{C}$ & $\mathrm{NC}$ & $\mathrm{C}$ & $\mathrm{C}$ & $\mathrm{C}$ & $\mathrm{NC}$ & $\mathrm{C}$ & $\mathrm{NC}$ & $\mathrm{EE}$ & $\mathrm{NC}$ & DND & $\mathrm{C}$ & $\mathrm{C}$ & $\mathrm{C}$ & $\mathrm{EE}$ & $\begin{array}{c}9 \mathrm{C}(52,9 \%) \\
3 \mathrm{EE}(17,6 \%) \\
4 \mathrm{NC}(23,5 \%) \\
1 \mathrm{DND}(5,8 \%)\end{array}$ \\
\hline $\begin{array}{l}\text { CATEGORIAS E } \\
\text { VARIÁVEIS }\end{array}$ & \multicolumn{17}{|c|}{ ESTADOS LATINO-AMERICANOS } & $\begin{array}{c}\text { FREQUÊENCIA } \\
(\%)\end{array}$ \\
\hline & $\mathbf{A R}$ & BO & BR & $\mathbf{C L}$ & CO & $\mathbf{C R}$ & EC & GT & HN & MX & NI & $\mathbf{P A}$ & $\mathbf{P E}$ & PY & SV & UY & VE & \\
\hline $\begin{array}{l}\text { Resultados da revisão de } \\
\text { qualidade de dados usados para } \\
\text { ajustar o número de pessoas em } \\
\text { tratamento. }\end{array}$ & DND & Sim & Sim & DND & DND & Sim & Sim & DND & Sim & DND & DND & DND & DND & Sim & DND & Sim & DND & $\begin{array}{c}7 \operatorname{Sim}(41,1 \%) \\
10 \operatorname{DND}(58,8 \%)\end{array}$ \\
\hline $\begin{array}{l}\text { Itens relativos às políticas de } \\
\text { prevenção do HIV para os } \\
\text { grupos de risco. }\end{array}$ & & & & & & & & & & & & & & & & & & \\
\hline $\begin{array}{l}\text { Profissionais do sexo } \\
\end{array}$ & & & & & & & & & & & & & & & & & & \\
\hline $\begin{array}{l}\text { Estratégia de prevenção para } \\
\text { profissionais do sexo e seus } \\
\text { clientes. } \\
\text { Metas nacionais de prevenção } \\
\text { do HIV para profissionais do } \\
\text { sexo para } 2020 \text { definidas. }\end{array}$ & Não & $\operatorname{Sim}$ & Sim & Não & Sim & Não & Sim & Sim & Sim & Não & Sim & Sim & DND & Sim & $\operatorname{Sim}$ & Sim & Sim & $\begin{array}{l}14 \operatorname{Sim}(82,3 \%) \\
2 \text { Não }(11,7 \%) \\
1 \text { DND }(5,8 \%) \\
8 \operatorname{Sim}(47,1 \%) \\
8 \text { Não }(47,1 \%) \\
1 \text { DND }(5,8 \%)\end{array}$ \\
\hline $\begin{array}{l}\text { Homens que fazem sexo com } \\
\text { homens }\end{array}$ & & & & & & & & & & & & & & & & & & \\
\hline $\begin{array}{l}\text { Estratégia de prevenção para } \\
\text { gays e outros homens que } \\
\text { fazem sexo com homens. }\end{array}$ & Não & Sim & Sim & Sim & Sim & Sim & Sim & Sim & Sim & Sim & Sim & Sim & DND & Sim & Sim & Sim & Sim & $\begin{array}{c}15 \operatorname{Sim}(88,2 \%) \\
1 \text { Não }(5,8 \%) \\
1 \text { DND }(5,8 \%)\end{array}$ \\
\hline
\end{tabular}




\begin{tabular}{|c|c|c|c|c|c|c|c|c|c|c|c|c|c|c|c|c|c|c|}
\hline \multirow{2}{*}{$\begin{array}{l}\text { CATEGORIAS E } \\
\text { VARIÁVEIS }\end{array}$} & \multicolumn{17}{|c|}{ ESTADOS LATINO-AMERICANOS } & \multirow{2}{*}{$\begin{array}{c}\text { FREQUÊNCIA } \\
(\%)\end{array}$} \\
\hline & $\mathbf{A R}$ & BO & BR & $\mathbf{C L}$ & $\mathrm{CO}$ & $\mathbf{C R}$ & EC & GT & HN & MX & NI & PA & PE & PY & SV & UY & $\mathbf{V E}$ & \\
\hline $\begin{array}{l}\text { Metas nacionais de prevenção } \\
\text { do HIV para HSH para } 2020 \\
\text { definidas. }\end{array}$ & Não & Sim & Não & Não & Não & Sim & Sim & Sim & Sim & Sim & Não & Sim & DND & Sim & Não & Não & Não & $\begin{array}{l}8 \operatorname{Sim}(47,1 \%) \\
8 \text { Não }(47,1 \%) \\
1 \text { DND }(5,8 \%)\end{array}$ \\
\hline \multicolumn{19}{|l|}{ Pessoas que injetam drogas } \\
\hline $\begin{array}{l}\text { As políticas nacionais excluem } \\
\text { as pessoas que atualmente } \\
\text { usam drogas de receber TARV. } \\
\text { Programas de agulhas e } \\
\text { seringas operacionais. }\end{array}$ & Não & Não & Não & Não & Não & Não & Não & Não & Não & Não & Não & Sim & DND & Não & Não & Não & Não & $\begin{array}{c}1 \text { Sim }(5,8 \%) \\
15 \text { Não }(88,2 \%) \\
1 \text { DND }(5,8 \%) \\
1 \text { Sim }(5,8 \%) \\
16 \text { Não }(94,1 \%)\end{array}$ \\
\hline $\begin{array}{l}\text { CATEGORIAS E } \\
\text { VARIÁVEIS }\end{array}$ & \multicolumn{17}{|c|}{ ESTADOS LATINO-AMERICANOS } & $\begin{array}{c}\text { FREQUENNCIA } \\
(\%)\end{array}$ \\
\hline & $\mathbf{A R}$ & BO & BR & CL & $\mathrm{CO}$ & CR & EC & GT & HN & MX & NI & PA & PE & PY & SV & $\mathbf{U Y}$ & VE & \\
\hline $\begin{array}{l}\text { Programas de terapia de } \\
\text { substituição de opioides } \\
\text { operacionais. }\end{array}$ & Não & Não & Não & Não & Sim & Sim & Não & Não & Não & Sim & Não & Não & Não & Não & Não & Não & Não & $\begin{array}{c}3 \operatorname{Sim}(17,6 \%) \\
14 \text { Não }(82,3 \%)\end{array}$ \\
\hline \multicolumn{19}{|l|}{ Prisioneiros } \\
\hline $\begin{array}{l}\text { Prisões: preservativos e } \\
\text { lubrificantes disponíveis. } \\
\text { Prisões: testes de HIV são } \\
\text { sistematicamente oferecidos na } \\
\text { entrada e / ou saída. }\end{array}$ & Sim & Não & Sim & Não & Não & Não & Não & Não & Sim & Não & Não & Não & Não & Sim & Sim & Sim & Sim & $\begin{array}{c}11 \operatorname{Sim}(64,7 \%) \\
6 \text { Não }(35,2 \%) \\
7 \operatorname{Sim}(41,1 \%) \\
10 \text { Não }(58,8 \%)\end{array}$ \\
\hline \multicolumn{19}{|l|}{ Preservativos } \\
\hline $\begin{array}{l}\text { Estratégia / plano nacional de } \\
\text { preservativos. }\end{array}$ & Sim & Sim & Sim & Sim & Sim & Sim & Sim & Sim & Sim & Sim & Sim & Sim & DND & Sim & Sim & Sim & Sim & $\begin{array}{c}16 \operatorname{Sim}(94,1 \%) \\
1 \operatorname{DND}(5,8 \%) \\
15 \operatorname{Sim}(88,2 \%)\end{array}$ \\
\hline
\end{tabular}




\begin{tabular}{|c|c|c|c|c|c|c|c|c|c|c|c|c|c|c|c|c|c|c|}
\hline \multirow[t]{2}{*}{$\begin{array}{l}\text { CATEGORIAS E } \\
\text { VARIÁVEIS }\end{array}$} & \multicolumn{17}{|c|}{ ESTADOS LATINO-AMERICANOS } & \multirow{2}{*}{$\begin{array}{c}\text { FREQUÊNCIA } \\
(\%)\end{array}$} \\
\hline & $\mathbf{A R}$ & BO & BR & CL & $\mathrm{CO}$ & CR & EC & GT & HN & MX & NI & $\mathbf{P A}$ & $\mathbf{P E}$ & PY & SV & $\mathbf{U Y}$ & $\mathbf{V E}$ & \\
\hline $\begin{array}{l}\text { As necessidades nacionais de } \\
\text { preservativos foram estimadas. }\end{array}$ & Sim & Sim & Sim & Sim & Sim & Sim & Sim & Sim & Sim & Sim & Sim & Sim & DND & Sim & Não & Sim & Sim & $\begin{array}{c}15 \operatorname{Sim}(88,2 \%) \\
1 \text { Não }(5,8 \%) \\
1 \text { DND }(5,8 \%)\end{array}$ \\
\hline $\begin{array}{l}\text { Restrições de idade para acesso } \\
\text { a preservativos. }\end{array}$ & Não & Não & Não & Não & Não & Não & Não & Sim & Não & Não & Sim & Não & DND & Não & Não & Não & Não & $\begin{array}{c}2 \operatorname{Sim}(11,7 \%) \\
14 \text { Não }(82,3 \%) \\
1 \text { DND }(5,8 \%)\end{array}$ \\
\hline \multicolumn{19}{|l|}{$\begin{array}{l}\text { Itens relativos às estratégias } \\
\text { para a população jovem e } \\
\text { infecções sexualmente } \\
\text { transmissíveis. }\end{array}$} \\
\hline $\begin{array}{l}\text { Prevenção do HIV entre } \\
\text { meninas adolescentes, } \\
\text { mulheres jovens e seus } \\
\text { parceiros masculinos }\end{array}$ & & & & & & & & & & & & & & & & & & \\
\hline
\end{tabular}

\section{CATEGORIAS E}

VARIÁVEIS

ESTADOS LATINO-AMERICANOS

FREQUÊNCIA

(\%)

O país tem uma estratégia

nacional de prevenção para

reduzir novas infecções entre

meninas adolescentes,

mulheres jovens e seus

parceiros masculinos em

comunidades com alta

incidência de HIV.

$\begin{array}{lllllllllllllllll}\text { AR } & \text { BO } & \text { BR } & \text { CL } & \text { CO } & \text { CR } & \text { EC } & \text { GT } & \text { HN } & \text { MX } & \text { NI } & \text { PA } & \text { PE } & \text { PY } & \text { SV } & \text { UY } & \text { VE }\end{array}$




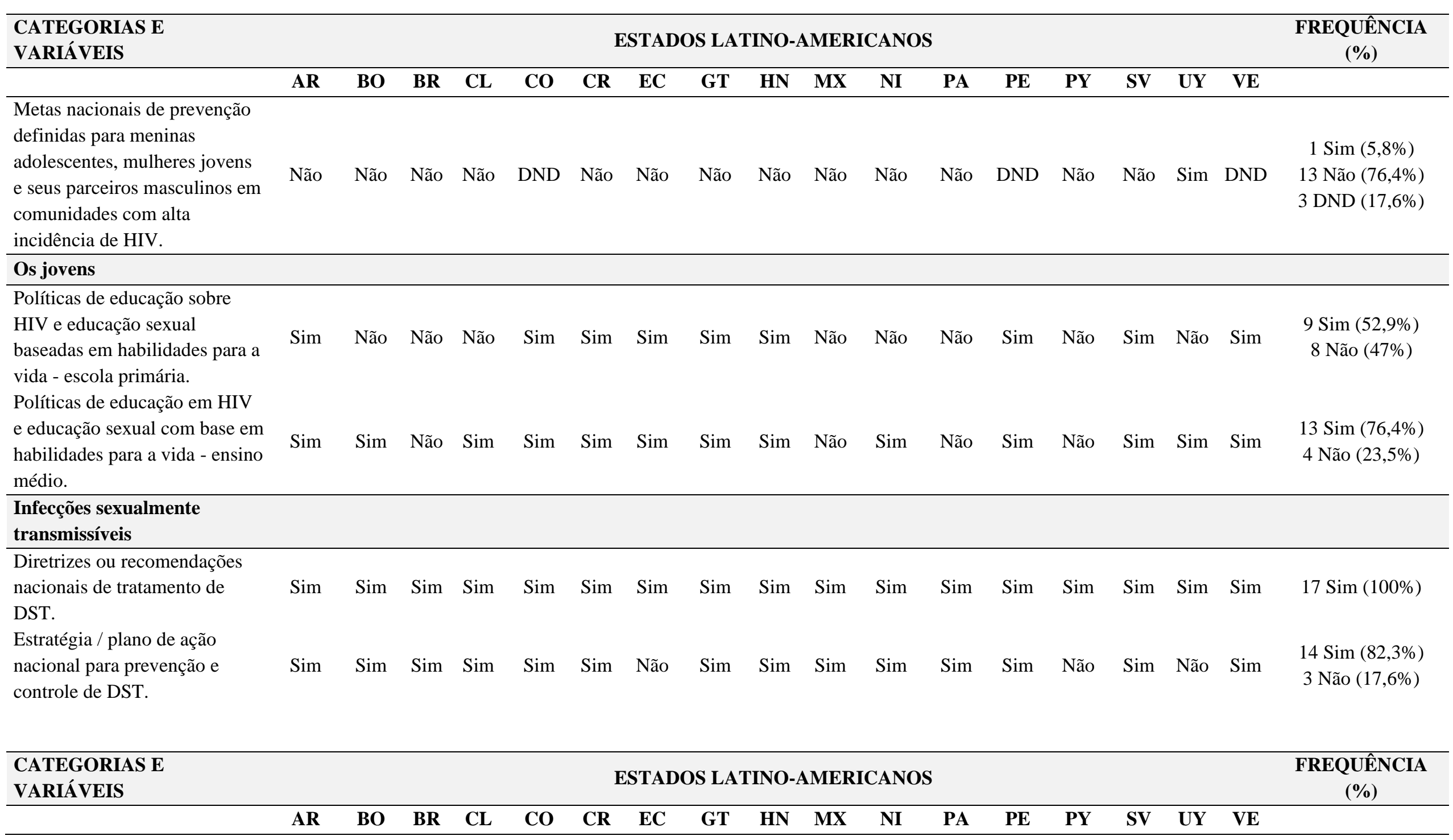




\begin{tabular}{|c|c|c|c|c|c|c|c|c|c|c|c|c|c|c|c|c|c|c|}
\hline \multirow[t]{2}{*}{$\begin{array}{l}\text { CATEGORIAS E } \\
\text { VARIÁVEIS }\end{array}$} & \multicolumn{17}{|c|}{ ESTADOS LATINO-AMERICANOS } & \multirow{2}{*}{$\begin{array}{c}\text { FREQUÊNCIA } \\
(\%)\end{array}$} \\
\hline & $\mathbf{A R}$ & BO & BR & CL & $\mathrm{CO}$ & CR & EC & GT & HN & MX & NI & PA & $\mathbf{P E}$ & PY & SV & UY & VE & \\
\hline \multicolumn{19}{|l|}{$\begin{array}{l}\text { Itens relativos às diretrizes de } \\
\text { atenção à saúde materna e a } \\
\text { transmissão vertical }\end{array}$} \\
\hline \multicolumn{19}{|l|}{$\begin{array}{l}\text { Prevenção da transmissão de } \\
\text { mãe para filho do HIV }\end{array}$} \\
\hline $\begin{array}{l}\text { O país tem uma política de } \\
\text { retestar mulheres HIV- } \\
\text { negativas durante a gravidez / } \\
\text { parto e / ou pós-parto / período } \\
\text { de amamentação. }\end{array}$ & Sim & Não & Sim & Não & Sim & Sim & Sim & Sim & Sim & Sim & Sim & Sim & DND & Sim & Sim & Sim & Não & $\begin{array}{l}13 \operatorname{Sim}(76,4 \%) \\
3 \text { Não }(17,6 \%) \\
1 \text { DND }(5,8 \%)\end{array}$ \\
\hline $\begin{array}{l}\text { O país tem um plano nacional } \\
\text { para eliminar a transmissão } \\
\text { vertical do HIV. }\end{array}$ & Sim & Não & Sim & Sim & Sim & Sim & Sim & Sim & Não & Sim & Sim & Sim & Sim & Sim & Sim & Sim & Não & $\begin{array}{l}14 \operatorname{Sim}(82,4 \%) \\
3 \text { Não }(17,6 \%)\end{array}$ \\
\hline $\begin{array}{l}\text { Taxa alvo de transmissão } \\
\text { vertical }^{c} \text {. }\end{array}$ & $<3,5 \%$ & $<2 \%$ & $2 \%$ & $<2 \%$ & $<2 \%$ & $0 \%$ & $<20 \%$ & $<2 \%$ & $<3 \%$ & $<8 \%$ & $<2 \%$ & $<1,5 \%$ & DND & $<2 \%$ & $<2 \%$ & $2 \%$ & DND & $\begin{array}{l}11<2 \%(64,7 \%) \\
4>2 \%(23,5 \%) \\
2 \text { DND }(11,7 \%)\end{array}$ \\
\hline \multicolumn{19}{|l|}{$\begin{array}{l}\text { Eliminação Da Transmissão } \\
\text { De Sífilis De Mãe Para Filho }\end{array}$} \\
\hline $\begin{array}{l}\text { Plano nacional para eliminar a } \\
\text { transmissão vertical da sífilis. } \\
\text { Política para triagem rotineira }\end{array}$ & Sim & Não & Sim & Sim & Sim & Sim & Sim & Sim & Sim & Sim & Sim & Sim & Sim & Sim & Sim & Sim & Não & $\begin{array}{l}15 \operatorname{Sim}(88,4 \%) \\
2 \text { Não }(11,7 \%)\end{array}$ \\
\hline $\begin{array}{l}\text { de mulheres grávidas para } \\
\text { sífilis. }\end{array}$ & Sim & Sim & Sim & $\operatorname{Sim}$ & Sim & Sim & Sim & Sim & Sim & Sim & Sim & Sim & Sim & Sim & Sim & Sim & Sim & $17 \operatorname{Sim}(\%)$ \\
\hline \multicolumn{19}{|l|}{ Diagnóstico infantil precoce } \\
\hline $\begin{array}{l}\text { Política sobre teste de ácido } \\
\text { nucleico para bebês expostos } \\
\text { ao HIV no nascimento. }\end{array}$ & Sim & Não & Sim & Sim & Não & Não & Sim & Sim & Sim & Sim & Sim & Sim & Não & Não & Não & Sim & Sim & $\begin{array}{l}11 \operatorname{Sim}(64,7 \%) \\
6 \text { Não }(35,2 \%)\end{array}$ \\
\hline
\end{tabular}




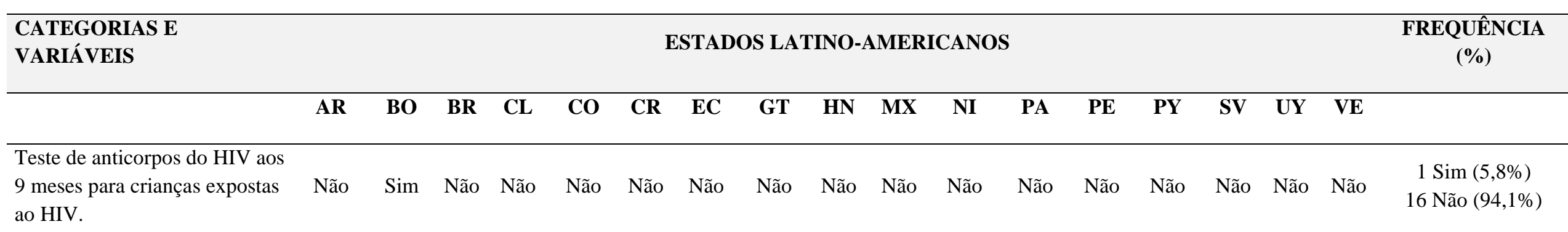

\section{Envolvimento Da \\ Comunidade Na Prevenção \\ Da Transmissão Vertical}

(PTV)

Reunião nacional realizada

para revisar o progresso da

PTV nos últimos 12 meses.

Fonte: Elaborada pelos autores com base em Laws and Policies (UNAIDS) (2020).

Nota a: Estudos PARTNER (Rodger A.J., et al., 2016); e OPPOSITES ATTRACT, (Bavinton, B.R., et al., 2018).

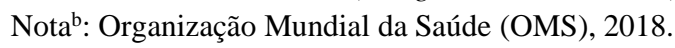

Notac $^{c}$ : Organização Pan-americana de Saúde (OPAS), 2014.

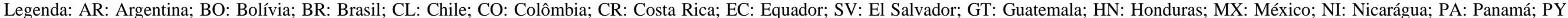

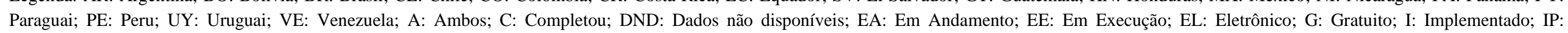

Parcialmente;

M: Meses;

NC: Nunca

Conduzido; NI:

Não Implementado;

P:Parcialmente;

PP:

Papel;

$\mathrm{T}$ :Total 
Somente 58,8\% dos países adotam como limiar de sucesso de supressão viral, o nível abaixo de 200 cópias $/ \mathrm{ml}$. Com relação à frequência, somente $47 \%$ dos países recomendam menos de 6 meses. Apenas 35,2\% dos países possuem sistemas implementados para monitorar a resistência aos medicamentos antirretrovirais. Em 52,9\% dos países, não há programas de alfabetização sobre tratamentos disponíveis para pessoas que vivem com HIV.

No tocante às Estratégias de Vigilância Epidemiológica (Tabela 1), o estudo revelou que apenas 41,1\% dos países tem vigilância sentinela conduzida para participantes da clínica pré-natal. Apenas 52,9\% dos países possuem a mesma estratégia para profissionais do sexo. Para essa estratégia, no grupo de HSH, o estudo revelou que 52,9\% dos países a possuem. Para o grupo de pessoas que injetam drogas, apenas $11,7 \%$ dos países possuem. Somente 17,6\% dos países notificaram que utilizam as diretrizes de monitoramento de pacientes da OMS 2017. No que refere à iniciativa 90-90-90, apenas 52\% dos países completaram a revisão da qualidade dos dados realizadas para determinar a precisão do número de pessoas em tratamento em nível nacional. Os resultados da revisão são disponíveis em apenas $41,1 \%$ dos países.

No que concerne aos itens das Políticas de Prevenção do HIV para os Grupos de Risco (Tabela 1), revelou-se que apenas 5,8\% dos países têm um programa de agulhas e seringas operacionais e 17,6\% têm um programa de terapia de substituição de opioides. A variável Prevenção de HIV para Prisioneiros demonstrou que em apenas 64,7\% dos países, preservativos e lubrificantes estão disponíveis e em somente $41,1 \%$ dos países, testes de HIV são oferecidos sistematicamente na entrada e/ou na saída. Quanto à variável Preservativo como estratégia de prevenção, constatou-se que em 11,7\% dos países há restrição de idade para ter acesso a preservativos.

Em relação às Estratégias para a População Jovem e Infecções Sexualmente Transmissíveis (Tabela 1), apenas 35,2\% dos países têm uma estratégia nacional de prevenção para reduzir novas infecções entre meninas adolescentes, mulheres jovens e seus parceiros masculinos em comunidades com alta incidência de HIV. Além disso, somente 5,8\% dos países possuem metas nacionais de prevenção definidas para esse grupo. Apenas 52,9\% dos países possuem políticas de educação sobre HIV e educação sexual baseada em habilidades para a vida na escola primária. Esse índice é de 76,4\% para os que ofertam essa política no ensino médio. Dos países, 82,3\% possuem estratégia de ação nacional para a prevenção e controle de DST.

Quanto aos itens relativos às Diretrizes de Atenção à Saúde Materna e a Transmissão Vertical (Tabela 1), tem-se que 82,3\% dos países têm um plano nacional para eliminar a transmissão vertical do HIV. Contudo, apenas 64,7\% dos países adotam a taxa alvo de transmissão vertical menor que $2 \%$. Constatou-se ainda que $64,7 \%$ dos países possuem políticas de teste de ácido nucleico para bebês expostos ao HIV no nascimento. Ademais, ficou evidente que em apenas 58,8\% dos países houve reunião nacional para revisar o progresso da PTV nos últimos 12 meses.

\section{Discussão}

A AIDS continuará a ser um desafio para as futuras gerações e para uma resposta eficaz é urgente a reformulação de ações para deter a epidemia, considerando que não há solução de curto prazo eficaz para a erradicação da doença (Moura \& Lemos, 2016). Desse modo, sem a descoberta de uma vacina eficaz ou um avanço na conquista de uma medicação capaz de fornecer a cura, provavelmente eliminar a aids é uma realidade distante; entretanto, é possível reduzir novas infecções e melhorar a qualidade de vida dos portadores através de políticas públicas e esforços coletivos com comprometimento internacional entre os Estados (Moura \& Lemos, 2016; Narayan, et al., 2012).

A utilização precoce da terapia antirretroviral leva a uma queda de $96 \%$ na possibilidade da transmissão do vírus, podendo ser utilizada como uma estratégia de prevenção na gestão de saúde pública à medida que, quanto mais precoce os indivíduos se descobrirem infectados e iniciarem o tratamento adequado, menor o dano causado pelo HIV (Comparini et al., 2017). Desse modo, as políticas de diagnóstico assumem papel fundamental no controle da doença e, nessa circunstância, a 
OMS publicou em 2015 as diretrizes sobre os serviços de teste de HIV. O presente estudo, ao analisar essas recomendações, constatou que menos da metade dos países da América Latina adotaram-nas totalmente, o que evidencia defasagem na abordagem dessa temática. Essa limitação na gestão política fica ainda mais evidente quando este estudo demonstra que não são todos os países têm provisão de testes gratuita para toda a população.

Para a OMS, políticas nacionais de autotestes de HIV são fundamentais representando mais um passo frente aos esforços para aumentar a autonomia do indivíduo, descentralizar os serviços e criar demanda de testes de HIV entre aqueles não alcançados pelos serviços (Brasil, 2019). Todavia, o presente estudo revela que 82,3\% dos países não possuem política nacional de autoteste de HIV, contrapondo as evidências significativas da adoção e retardando a assistência ao paciente.

A partir do acesso em larga escala da população infectada pelo HIV/Aids à terapia antirretroviral (TARV), houve expressiva redução da morbidade e mortalidade dessas pessoas, reduziu-se o número de internações e aumentou-se a expectativa de vida (Padoin et al., 2013). Nesse contexto, considerando as evidências de uma política sólida de acesso à terapia retroviral, a OMS publicou em 2016 a segunda edição das diretrizes consolidadas sobre o uso de medicamentos antirretrovirais para tratamento e prevenção da infecção pelo HIV, com as recomendações de fornecimento da terapia antirretroviral ao longo da vida a todas as pessoas que vivem com o HIV, incluindo crianças, adolescentes e adultos, mulheres grávidas e lactantes, independentemente do estado clínico ou da contagem de células CD4 (OPAS Brasil, 2017).

Nessa conjuntura, esta pesquisa evidenciou que apenas $23,5 \%$ dos países completaram essas recomendações para a população adulta e apenas 41,1\% para a população pediátrica. Dois anos depois, em 2018, a OMS publicou novas atualizações sobre o uso de ARVs para o tratamento e prevenção do HIV; porém, o presente estudo demonstrou que ainda assim apenas $41,1 \%$ dos países concluíram essas recomendações, o que evidência a fragilidade da assistência à população junto às desatualizações das políticas nacionais nesse território.

A partir do estudo HPTN 052, a OMS reconheceu que quem vive com HIV, está em tratamento antirretroviral e tem carga viral indetectável, não transmite o vírus. Essa tese foi corroborada pelos estudos Opposites Attract (Bavinton et al., 2018) e PARTNER (Rodger et al., 2016), quando esses revelaram que não relataram nenhuma transmissão quando a carga viral era indetectável, abaixo de 200 cópias $/ \mathrm{mL}$ (Rodger, et al., 2016). A presente pesquisa ao avaliar as políticas dos países Latinoamericanos revelou que apenas 58,8\% adotam como limiar de sucesso de supressão de carga viral o ponto de corte igual ou inferior ao apresentado nos estudos Opposites Attract (Bavinton et al., 2018) e PARTNER (Rodger et al., 2016). Com relação à frequência recomendada para teste de carga viral, o UNAIDS postula que devam ser realizados duas a quatro vezes ao ano para manutenção da carga viral indetectável; contudo, nossos achados evidenciaram que somente $47 \%$ dos países recomendam em suas políticas nacionais a frequência de menos de 6 meses.

O Relatório 2017 Resistência a Medicamentos para HIV, da OMS, demonstrou que entre os países inspecionados na América Latina, África e Ásia, mais de $10 \%$ das pessoas que iniciaram a terapia antirretroviral apresentaram uma cepa de HIV resistente a alguns dos medicamentos mais amplamente utilizados para o HIV (UNAIDS Brasil, 2017). Dada a importância dessa temática, nossa pesquisa evidenciou que tão somente 35,2\% dos países Latino-americanos possuem sistemas implantados para monitorar a resistência aos medicamentos antirretrovirais, o que demonstra fragilidade na política de assistência à saúde. Nossos achados evidenciaram ainda que apenas $47 \%$ dos países afirmaram ter políticas nacionais que possuem programas de instrução às pessoas que vivem com o HIV a respeito dos tratamentos disponíveis, o que pode corroborar com o crescimento das taxas de resistência à terapia antirretroviral à medida que a resistência aos medicamentos contra o HIV se desenvolve quando as pessoas não aderem a um plano de tratamento prescrito (UNAIDS Brasil, 2017).

Considera-se vigilância sentinela o modelo de vigilância realizada a partir da vigilância de morbidade, mortalidade ou agentes etiológicos de interesse para a saúde pública, cujo objetivo é monitorar indicadores-chave em unidades de saúde selecionadas que sirvam como alerta precoce para o sistema de vigilância (Brasil, 2016). Nesse contexto, como publicado pela 
OMS, as falhas no provimento de serviços adequados em HIV aos grupos-chave - HSH, Pessoas Privadas de Liberdade, Pessoas que Usam Drogas Injetáveis, Profissionais do Sexo- ameaçam o progresso global da resposta ao HIV (Bittencourt, 2014). Há a necessidade de estratégia de vigilância maior para esses grupos, uma vez que apresentam maiores riscos de contaminação pelo agravo. Este estudo revelou que apenas 52,9\% utilizam a estratégia de vigilância sentinela para monitorar os dados das profissionais do sexo, $52,9 \%$ dos países a utilizam para monitorar a população de HSH e apenas $11,7 \%$ dos países, utilizam como política para a vigilância do grupo de pessoas que injetam drogas, o que demonstra a fragilidade das estratégias de vigilância epidemiológica na América Latina.

A respeito dos indicadores e ferramentas do sistema de monitoramento, este estudo chama atenção ainda ao dado de que apenas 17,6\% dos países Latino-americanos contemplaram as diretrizes de monitoramento de pacientes publicado pela OMS em 2017 para reforçar as recomendações mais eficazes para essa estratégia.

O UNAIDS, com objetivo de erradicar mundialmente a epidemia do HIV até 2030, projetou o plano da tríplice meta 90-90-90, prevendo metas de que 90\% de todas as pessoas vivendo com HIV sejam diagnosticadas, 90\% destas recebam terapia antirretroviral ininterruptamente e 90\% destas em tratamento apresentem supressão viral até 2020 (Bones et al., 2018). Contudo, esta pesquisa evidenciou que apenas $52 \%$ dos países completaram a revisão da qualidade dos dados prestados a essa política e somente em $41,1 \%$ dos países os dados dessa revisão da qualidade estão disponíveis, o que pode comprometer a efetividade da política.

A prevalência de HIV entre as pessoas privadas de liberdade é muito maior do que na população em geral, possuindo cinco vezes mais chances de viver com HIV em comparação com adultos em liberdade (UNAIDS Brasil, 2019b). Este estudo evidenciou que apenas 64,7\% dos países disponibilizam preservativos e lubrificantes para a população privada de liberdade e, em somente 41,1\% dos países, testes de HIV são oferecidos sistematicamente na entrada e/ ou na saída do sistema prisional. Essas medidas são reconhecidas como fundamentais na política de resposta o HIV/Aids demonstrando que há má gestão em boa parte dos países Latino-americanos.

Meninas adolescentes e mulheres jovens ainda são desproporcionalmente afetadas pelo HIV (ONU Mulheres, 2019). De acordo com a OMS, em 2015, o HIV/Aids foi a principal causa de morte entre mulheres em idade reprodutiva em países em desenvolvimento (ONU Mulheres, 2015). Em 2013, quase 60\% de todas as novas infecções por HIV entre jovens ocorreu entre meninas adolescentes e mulheres jovens (ONU Mulheres, 2015). O presente estudo evidenciou que apenas 35,2\% dos países têm uma estratégia nacional de prevenção para reduzir novas infecções entre esse grupo e somente 5,8\% dos países possuem metas nacionais de prevenção para o grupo.

Em janeiro de 2018, a UNESCO divulgou a publicação Orientação Técnica Internacional sobre Educação em Sexualidade. A publicação defende a educação sexual abrangente e de qualidade para promover a saúde e o bem-estar, o respeito aos direitos humanos e à igualdade de gênero e o empoderamento de crianças e os jovens para levarem vidas saudáveis e seguras (UNESCO, 2018). Entretanto, esta pesquisa verificou que apenas 52,9\% dos países possuem políticas sobre educação sexual e HIV na escola primária e 76,4\% ofertam essa política de ensino para o ensino médio; o que demostra fragilidade no sistema educacional e a perda de oportunidade de educação permanente em saúde pelos Estados. É válido salientar, ainda, que em 88,2\% dos países não há restrição de idade para ter acesso a preservativo; contudo, o ponto de reflexão proposto neste estudo não é o livre acesso ao preservativo e sim o acesso amplo sem recomendações de correta utilização, ensino e orientação sobre as infecções sexualmente transmissíveis.

A transmissão vertical é a principal via de infecção pelo HIV na população infantil. Estima-se que $15 \%$ a $30 \%$ das crianças nascidas de mães soropositivas para o HIV adquirem o vírus na gestação, durante o trabalho de parto ou parto, ou por meio da amamentação (Brasil, 2007). A literatura mostra uma redução dessa taxa para níveis entre $1 \%$ a $2 \%$ com a aplicação de todas as intervenções preconizadas pelo Programa Nacional de DST e Aids; entre elas a indicação da terapia antirretroviral. 
Para isso, faz-se necessário o diagnóstico precoce da gestante para que, o quanto antes, ela adentre ao programa de terapia medicamentosa e reduza os riscos de complicações para ela e seu filho.

Nesse cenário, a presente pesquisa demonstrou que aproximadamente $25 \%$ desses não tem uma política de retestar mulheres HIV negativas durante a gravidez, parto, pós-parto e período de amamentação; o que claramente vai de encontro às recomendações cientificas internacionais. Além disso, apesar de 82,3\% dos países possuírem um plano nacional para eliminar a transmissão vertical do HIV, apenas $64,7 \%$ adotam a taxa alvo de transmissão vertical menor que $2 \%$, como recomendado pela Organização Pan-Americana da Saúde (OPAS) (Gomes et al., 2015). Essas evidências somam-se, revelando que há a necessidade de ajustar as políticas nacionais entre os países em busca de uma ação sinérgica para o fim da transmissão vertical.

Os programas criados para fornecer terapia antirretroviral (TARV) para gestantes e crianças reduziram o número anual de novas infecções na infância e mortes em crianças em 33\% nos últimos anos (Weinberg, 2018). Desse modo, garantir a TARV às crianças infectadas que ainda não recebem tão frequentemente quanto os adultos, e interromper a transmissão vertical são os dois objetivos mais importantes da medicina pediátrica global contra o HIV (Weinberg, 2018). Assim, é de importância ímpar o diagnóstico precoce do recém-nascido para a assistência terapêutica.

O diagnóstico da infecção pelo HIV para a população pediátrica deve respeitar a presença de anticorpos passivamente recebidos da mãe; assim, deve ser feito através de testes de amplificação de ácidos nucleicos (como o PCR) em crianças menores de 18 meses e através da detecção de anticorpos virais para as maiores de 18 meses (Weinberg, 2018). O presente estudo revelou que apenas $64,7 \%$ dos países possuem políticas de teste de ácidos nucleicos para bebês expostos ao HIV e evidenciou também que ainda há países utilizando testes de anticorpos do HIV antes dos 18 meses para crianças expostas ao HIV, comprometendo o diagnóstico destes.

O presente estudo revelou que ao analisar os países da América Latina houve consideráveis discrepâncias na adoção das leis e políticas recomendadas pelo UNAIDS. Essa variação entre os países que se destacaram e os que menos comtemplaram foi de 50\%, o que claramente vai de encontro às indicações de condutas na construção dos planos nacionais de estratégias de enfrentamento ao HIV/AIDS. Assim sendo, tal prática revela comprometimento da eficácia das gestões da região da Latino-americanos. Ao se analisar as recomendações do UNAIDS por tipo de estratégias e políticas fica ainda mais evidente que há ineficaz condução nas políticas de combate ao HIV/AIDS à medida que este estudo demonstra que há estratégias que são mais priorizadas e outras menos; porém, todas são de fundamental importância. É valido ressaltar que mesmo as estratégias mais contempladas ainda se apresentam abaixo do recomendado.

\section{Conclusão}

Desta forma, conclui-se que há a necessidade de reajuste das estratégias de ações propostas para a resposta ao HIV/Aids, com o intuito de uniformidade de planos de medidas comprovadamente eficazes entre os países Latino-americanos. A partir de então será possível vislumbrar a plausibilidade do fim desse agravo que há tempos compromete a vida, a qualidade desta e dispendia recursos econômicos e humanos.

Por ser um trabalho de caráter pioneiro na América Latina, este pode servir de base para a elaboração de mais estudos na área, bem como incentivar os gestores a traçarem políticas nacionais mais ajustadas aos esforços internacionais visando a prevenção, diagnóstico e tratamento da aids, garantindo políticas públicas para a melhoria da saúde universal.

\section{Referências}

Almeida, L. M. D. (2005). Da prevenção primordial à prevenção quaternária. Revista Portuguesa de Saúde Pública, 23(1), 91-96.

AVERT (2020). Hiv And Aids In Latin America The Caribbean Regional Overview. <https://www.avert.org/professionals/hiv-around-world/latinamerica/overview>. 
Ayres, J. R. C. M., França Júnior, I., Calazans, G. J., \& Saletti Filho, H. C. (2003). O conceito de vulnerabilidade e as práticas de saúde: novas perspectivas e desafios. Promoção da saúde: conceitos, reflexões, tendências, 2, 121-144.

Bavinton, B. R., Pinto, A. N., Phanuphak, N., Grinsztejn, B., Prestage, G. P., Zablotska-Manos, I. B., Jin, F., Fairley, C. K., Moore, R., Roth, N., Bloch, M., Pell, C., McNulty, A. M., Baker, D., Hoy, J., Tee, B. K., Templeton, D. Cooper, D. A., Emery, S., Kelleher, A., Grulich, A. E., ... \& Orth, D. (2018). Viral suppression and HIV transmission in serodiscordant male couples: an international, prospective, observational, cohort study. The lancet HIV, 5(8), e438-e447.

Bittencourt, C. (2014). OMS: pessoas que estão sob maior risco ao HIV não estão tendo acesso aos serviços de saúde que necessitam. <https://www.unasus.gov.br/noticia/oms-pessoas-que-estao-sob-maior-risco-ao-hiv-nao-estao-tendo-acesso-aos-servicos-de-saude>.

Bones, A. A. N. D. S., Costa, M. R. D., \& Cazella, S. C. (2018). A educação para o enfrentamento da epidemia do HIV. Interface-Comunicação, Saúde, Educação.

Brasil (2007). Protocolo para a prevenção de transmissão vertical de HIV e sífilis. Recuperado de: http://bvsms.saude.gov.br/bvs/publicacoes/protocolo_prevencao_transmissao_verticalhivsifilis_manualbolso.pdf

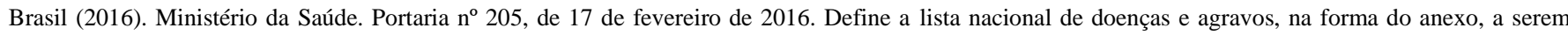
monitorados por meio da estratégia de vigilância em unidades sentinelas e suas diretrizes. <http://bvsms.saude.gov.br/bvs/saudelegis/gm/2016/prt0205_17_02_2016.html>.

Brasil (2019). O que é um autoteste? <http://www.aids.gov.br/pt-br/autoteste/o-que-e-um-autoteste>.

Butturi Junior, A. (2019). O hiv, o ciborgue, o tecnobiodiscursivo. Trabalhos em Linguística Aplicada, 58(2), 637-657.

Comparini, R. A., Silva, E. T. D., \& Pereira, D. C. R. (2017). Estratégias de ampliação do diagnóstico da infecção pelo Vírus da Imunodeficiência Humana no Brasil, 2015.

Gomes, D. M., Oliveira, M. I. C. D., \& Fonseca, S. C. (2015). Avaliação da testagem anti-HIV no pré-natal e na assistência ao parto no Rio de Janeiro, Brasil. Revista Brasileira de Saúde Materno Infantil, 15(4), 413-423.

Leite, J. L., Leite, J. L., Dantas, C. D. C., Da Silva, C. C., \& Gonçalves da Silva, D. (2006). Aids: vinte quatro anos de luta. Enfermería global, 9, 1-13.

Lopes, A. C. M. U., Araújo, M. A. L. D., Vasconcelo, L. D. P. G., Uchoa, F. S. V., Rocha, H. P., \& Santos, J. R. D. (2016). Implantação dos testes rápidos para sífilis e HIV na rotina do pré-natal em Fortaleza-Ceará. Revista Brasileira de Enfermagem, 69(1), 62-66.

Moura, L. N., \& Lemos, S. M. A. (2016). Políticas públicas de saúde e ações de promoção da saúde em HIV/AIDS: revisão da literatura. Revista Médica de Minas Gerais, 26(Supl 8), S256-S259.

Narayan, K. V., Ali, M. K., del Rio, C., Koplan, J. P., \& Curran, J. (2011). Global noncommunicable diseases-lessons from the HIV-AIDS experience. New England Journal of Medicine, 365(10), 876-878.

ONU Mulheres (2015). Quase 60\% de todas as novas infecções por HIV entre jovens ocorreu em meninas adolescentes e mulheres. <http://www.onumulheres.org.br/noticias/quase-60-de-todas-as-novas-infeccoes-por-hiv-entre-jovens-ocorreu-em-meninas-adolescentes-e-mulheres/>.

OPAS Brasil (2017). Folha informativa - HIV/aids. <https://www.paho.org/bra/index.php?option=com content\&view=article\&id=5666:folha-informativahiv-aids\&Itemid=812>.

Organização das Nações Unidas (ONU) (2019). HIV na América Latina e Caribe. https://nacoesunidas.org

Padoin, S. M. M., Zuge, S. S., dos Santos, É. E. P., Primeira, M. R., Aldrighi, J. D., \& de Paula, C. C. (2013). Adesão à terapia antirretroviral para HIV/AIDS. Cogitare Enfermagem, 18(3).

Paksoy, N. (2019). Simultaneous occurrence of Kaposi sarcoma and tuberculosis; Kaposi sarcoma and lymphoma in the same lymph node: a report on two HIV-positive patients from Zimbabwe. Revista da Sociedade Brasileira de Medicina Tropical, 52.

Pereira, A. S., Shitsuka, D. M., Parreira, F. J., \& Shitsuka, R. (2018). Metodologia da pesquisa científica. <http://repositorio.ufsm.br/bitstream/handle/1/15824/Lic_Computacao_Metodologia-Pesquisa-Cientifica.pdf?sequence=1>.

Rabkin, M., \& El-Sadr, W. M. (2011). Why reinvent the wheel? Leveraging the lessons of HIV scale-up to confront non-communicable diseases. Global public health, 6(3), 247-256.

Rodger, A. J., Cambiano, V., Bruun, T., Vernazza, P., Collins, S., Van Lunzen, J., Corbelli, G. M., Estrada, V. Geretti, A. M., Beloukas, A., Asboe, D., Viciana, P., Gutiérrez, F., Clotet, B., Pradier, C., Gerstoft, J., Weber, R., Westling, K., Wandeler, G., Prins, J. M., Rieger, A., Stoeckle, M., Kummerle, T., Bini, T., Ammassari, A., Gilson, R., Krznaric, I., Ristola, M., Zangerle, R., Handberg, P., Antela, A., Allan, S. Phillips, A. N., Lundgren, J, \& PARTNER Study Group. (2016). Sexual activity without condoms and risk of HIV transmission in serodifferent couples when the HIV-positive partner is using suppressive antiretroviral therapy. Jama, 316(2), 171-181.

UNAIDS Brasil (2017). OMS chama atenção para risco de resistência a medicamentos para HIV. Recuperado de: <https://unaids.org.br/2017/07/oms-atencaoameaca-resistencia-medicamentos-hiv/\#: :text=A\%20resist $\%$ C3\%AAncia\%20aos\%20medicamentos $\% 20$ contra,de $\% 20$ qualidade $\% 20$ para $\% 20$ o $\% 20 \mathrm{HIV}>$.

UNAIDS Brasil (2019a). Estatísticas 2019. https://unaids.org.br/estatisticas/

Unaids Brasil (2019b). Pessoas privadas de liberdade necessitam de serviços básicos de HIV. Brasília: Unaids Brasil. <https://unaids.org.br/2019/10/muitaspessoas-privadas-de-liberdade-necessitam-de-servicos-basicos-de-

hiv/\#: :text=Mundialmente\%2C\%20a\%20preval\%C3\%AAncia\%20de\%20HIV,compara\%C3\%A7\%C3\%A3o\%20com\%20adultos\%20em\%20liberdade>. 
Research, Society and Development, v. 10, n. 14, e352101421905, 2021

(CC BY 4.0) | ISSN 2525-3409 | DOI: http://dx.doi.org/10.33448/rsd-v10i14.21905

UNESCO (2018). Orientação Técnica Internacional sobre Educação em Sexualidade: Uma abordagem baseada em evidências para escolas, professores e educadores em saúde. 〈https://www.gcedclearinghouse.org/sites/default/files/resources/170106por.pdf>.

Villarinho, M. V., Padilha, M. I., Berardinelli, L. M. M., Borenstein, M. S., Meirelles, B. H. S., \& Andrade, S. R. D. (2013). Políticas públicas de saúde face à epidemia da AIDS e a assistência às pessoas com a doença. Revista Brasileira de Enfermagem, 66(2), 271-277.

Weinberg, G. A. (2018). Infecção pelo vírus da imunodeficiência humana (HIV) em lactentes e crianças <https://www.msdmanuals.com/pt/profissional/pediatria/infec\%C3\%A7\%C3\%A3o-pelo-v\%C3\%ADrus-da-imunodefici\%C3\%AAncia-humana-hiv-emlactentes-e-crian\%C3\%A7as/infec\%C3\%A7\%C3\%A3o-pelo-v\%C3\%ADrus-da-imunodefici\%C3\%AAncia-humana-hiv-em-lactentes-e-crian\%C3\%A7as. 